\title{
Music-based cognitive remediation therapy for patients with traumatic brain injury
}

\section{Shantala Hegde*}

Cognitive Psychology and Cognitive Neurosciences Laboratory, Department of Clinical Psychology, Neurobiology Research Center, National Institute of Mental Health and Neuro Sciences (NIMHANS), Bangalore, India

\section{Edited by:}

Robert Martyn Bracewell, Bangor

University, UK

Reviewed by:

Firas H. Kobeissy, University of

Florida, USA

Zhihui Yang, University of Florida, USA

\section{*Correspondence:}

Shantala Hegde, Cognitive

Psychology and Cognitive

Neurosciences Laboratory,

Neurobiology Research Center,

National Institute of Mental Health

and Neuro Sciences, \#203, Hosur

Road, Bangalore-560029, KA, India;

Department of Clinical Psychology,

Govindaswamy Center, NIMHANS,

\#313, 3rd Floor, Hosur Road,

Bangalore-560029, KA, India

e-mail: shantalah@nimhans.kar.nic.in

shantala.hegde@gmail.com
Traumatic brain injury (TBI) is one of the common causes of disability in physical, psychological, and social domains of functioning leading to poor quality of life. TBI leads to impairment in sensory, motor, language, and emotional processing, and also in cognitive functions such as attention, information processing, executive functions, and memory. Cognitive impairment plays a central role in functional recovery in TBI. Innovative methods such as music therapy to alleviate cognitive impairments have been investigated recently. The role of music in cognitive rehabilitation is evolving, based on newer findings emerging from the fields of neuromusicology and music cognition. Research findings from these fields have contributed significantly to our understanding of music perception and cognition, and its neural underpinnings. From a neuroscientific perspective, indulging in music is considered as one of the best cognitive exercises. With "plasticity" as its veritable nature, brain engages in producing music indulging an array of cognitive functions and the product, the music, in turn permits restoration and alters brain functions. With scientific findings as its basis, "neurologic music therapy" (NMT) has been developed as a systematic treatment method to improve sensorimotor, language, and cognitive domains of functioning via music. A preliminary study examining the effect of NMT in cognitive rehabilitation has reported promising results in improving executive functions along with improvement in emotional adjustment and decreasing depression and anxiety following TBI. The potential usage of music-based cognitive rehabilitation therapy in various clinical conditions including TBI is yet to be fully explored. There is a need for systematic research studies to bridge the gap between increasing theoretical understanding of usage of music in cognitive rehabilitation and application of the same in a heterogeneous condition such as TBI.

Keywords: traumatic brain injury, cognitive rehabilitation, neurologic music therapy, neuromusicology, music cognition, music therapy

\section{TRAUMATIC BRAIN INJURY AND ITS SEQUELAE}

Traumatic brain injury (TBI), an injury to the brain from an external agent or force, is one of the leading causes of disability in multiple domains of functioning. TBI may cause transient or long lasting impairment in neurological and neuropsychological functioning (1). Injury may be primary or secondary in nature. Primary injury is the direct impact of the external agent causing injury to the brain. Secondary injury is due to disordered autoregulation or any other pathophysiological changes within the brain following the injury. Hypoxic or ischemic injuries which may be a primary or secondary injury affect recovery. Depending upon the site of injury (focal or diffuse) and severity of the injury (mild, moderate, or severe), impairment is observed in the physical, psychological, and social domains of functioning. These impairments may be transient or long lasting in nature (2-5). The TBI sequelae includes physical sequelae which may be in the form of motor dysfunctions, hemiplegia, visual impairment, auditory impairment, deficits in gait etc; psychological sequelae in the form of deficits in cognitive functions and emotional problems; social sequelae in the form of loss of family or friends, or changes in the social relationship, changes in routine activities, loss of job or loss of work-related skills, inability to acquire new skills, and financial problems. It is the psychological and social consequences of TBI that are far more disabling and burdensome to the individual, the caregivers as well as the society at large $(3,6-8)$. The psychological and social sequelae may be observed immediately after the injury or after lapse of time. This may or may not be in concurrence with physical disability. Physical dysfunctions are easily detectable and often not a major problem in mild injury. The severity of TBI is associated positively with severity of psychosocial functioning. Cognitive deficits such as deficits in attention, information processing, planning, decision-making, memory, language, and emotional processing have significant impact on personal and socio-occupational functioning. Cognitive deficits are considered to play a central role in TBI and contribute significantly to functional recovery $(4,9)$.

\section{COGNITIVE REMEDIATION IN TBI}

In the past three and half decade, cognitive remediation (CR) has emerged as one of the best available treatment methods to restore cognitive functions and facilitate compensatory strategies 
to overcome cognitive deficits following TBI or other acquired brain injury conditions (10-15). CR is described as "procedures designed to provide patients with the behavioral repertoire needed to solve problems or to perform tasks that seem difficult or impossible" (16). The terms rehabilitation and remediation conveys specific approach to treatment, although the two terms have been interchangeably used in literature to discuss treatment strategies aiming at skills development in patients needed to perform tasks that are difficult to perform due to cognitive deficits. In a technical sense, rehabilitation involves a wide array of interventions offered by a multidisciplinary team. CR comes under the umbrella of a broader treatment approach, i.e., rehabilitation (17). Cognitive rehabilitation includes methods such as remediation, compensation, and holistic or multimodal programs $(6,18)$. Cognitive rehabilitation is a confluence of therapeutic activities based on brain-behavior relationships. Functional improvement is achieved by re-establishing or reinforcing previously learned adaptive patterns of behavior, facilitating improvement in cognitive functions through compensatory mechanisms and sometimes facilitating new patterns of activity through external compensatory mechanisms. The goal of cognitive rehabilitation is to help patients with cognitive deficits to adapt to their disability to improve overall functioning. The holistic approach addresses the cognitive, emotional, and other non-cognitive domains of functioning as well as addresses rehabilitation in social milieu and facilitating patient to have better understanding of one's own reaction to the consequences of brain injury (19-22). Evidence exists to support benefits of CR in improving cognitive functions such as attention, memory aphasia, functional communication, and unilateral spatial neglect $(11,12,23)$. Systematic reviews on a total of 370 intervention studies on CR in TBI and other acquired brain injury have concluded that there is substantial evidence to support benefits of CR in TBI $(13,24)$. Meta-analysis has shown a small treatment effect size $(d=0.30)$ to large effect size $(d=0.71)$, variable due to the design of the research studies with larger effect size observed in single group pre-test and post-test comparison studies. The outcome was influenced by moderating variables such as the specific cognitive function targeted in intervention, duration between injury to treatment onset, the type of injury, and age of patients included in the intervention studies (13). Interventions to remediate cognitive deficits have often employed either paper-pencil or computer-based tasks that would enable direct training of the cognitive function as well as metacognitive training methods (i.e., self-monitoring and self-regulation) to facilitate compensatory strategies and to facilitate generalization to real-world situations (12). The most often evaluated treatment approach in the published literature aims to directly retrain the cognitive function that is impaired via cognitive drills and exercises targeting the specific cognitive function (25). Repeated practice on carefully designed exercises is considered to facilitate recovery of the damaged neural circuits and restoration of function such as attention, memory, executive functions, etc. The tasks mediated by these circuits would then lead to a near normal or normal level of functioning as comparable to the functioning due to an intact brain without any injury $(16,26-28)$. A careful examination of literature on CR in acquired brain injury indicates a lack of high-quality evidenced-based research studies and fraught by lack of generalizability of improvement on cognitive functions targeted in the treatment sessions to real-life situations $(23,29-31)$.

\section{MUSIC-BASED INTERVENTION AS A TECHNIQUE OF CR}

Many innovative methods to treat TBI sequelae have been developed over the years. Music therapy is one such method. Musicbased intervention methods have shown promising results in rehabilitating movement, gait-related problems (32). It has shown positive results in reducing the levels of anxiety, depression, agitation and in inducing stable mood state. Enhanced adaptive behavior following music-based intervention has been observed even during recovery from coma and later in both adult and children population (33-39). Music-based intervention has led to improvement in speech production and sensory perceptions $(40,41)$. Studies suggest that use of musical intervention facilitates early responsiveness in patients which in turn foster cognitive rehabilitation in the early acute phase following TBI (39). The more recent frontier is music-based $\mathrm{CR}$ in various neurological and neurosurgical conditions $(33,35)$. The application of music in CR is although a recent endeavor, the potential of music in this area of rehabilitation was put forth much earlier (42).

The use of music as a therapeutic method has a long history, perhaps dates back to prehistoric times driven by the social science model wherein music is interpreted as a facilitator of "well-being" and enhancing emotional health $(43,44)$. This very nature of music to reduce stress and enhance emotional health has started receiving scientific evidence from studies examining the neurochemical changes that occur when listening to or engaged in music actively. The two important markers of stress regulated by the hypothamalic-pituitary-adrenal axis (HPA or HTPA), the beta endorphin and cortisol levels have been observed to decrease significantly with music intervention (45-47). A recent review has examined the scientific work supporting therapeutic effect of music using neurochemical changes as evidence. The authors of this review work compile the evidences in four different domains viz., (a) reward, motivation, and pleasure mediated by dopamine and opioids; (b) stress and arousal mediated by cortisol, corticotropin-releasing hormone ( $\mathrm{CRH})$, and adrenocorticotropic hormone $(\mathrm{ACTH})$; (c) immunity mediated by serotonin and the peptide derivatives of proopiomelanocortin (POMC), alpha-melanocyte-stimulating hormone and beta-endorphin; (d) social affiliation mediated by oxytocin (48). It is also hypothesized that listening to music facilitates neurogenesis or the regeneration and repair of cerebral nerves by adjusting the secretion of steroid hormones, finally leading to neural plasticity (49). Intensely pleasurable music or anticipation of a peak emotional experience whilst listening to music is known to engage the very same areas involved in other real-life emotions such as mesolimbic, the reward area of the brain, the nucleus accumbens, and an increase in dopamine levels (50-53). In fact evidence-based approach to understanding the benefits of music, especially in the area of neurological rehabilitation has been a recent endeavor (54, 55). The neurochemical marker of neural plasticity, viz., brainderived neurotrophic factor (BDNF) as a marker of cognitive 
improvement via music-based intervention is an area of investigation yet to be carried out. Advancement in research techniques and tools to study neural correlates of cognitive processes and functions such as EEG/ERP, fMRI, TMS, rTMS, etc has brought newer insights into the underlying process and therapeutic benefits of music-based intervention. A paradigm shift in the field of music therapy has been significantly influenced by the growth in the areas of neuromusicology, music cognition, and neurochemistry of musical process. The shift in music therapy from a social science and interpretive models to neuroscientific models has been set forth (44).

In the field of neuroscience today, music is considered as a powerful tool to understand brain functions and music-brainbehavior interactions. Music engages a host of cognitive processes such as acoustic analysis, information processing, sensory motor integration, learning, memory, decision making, emotion, and creativity. The neuroscientific models of music therapy is based on the principle that, "plasticity" as its veritable nature, brain engages in producing music by indulging an array of cognitive functions and in turn gets restored and altered via music even in the non-musical domains of functioning. In other words, music can stimulate complex cognitive, affective, and sensorimotor processes in the brain that can be generalized and transferred to non-musical therapeutic applications (56-61).

Scientific evidence linking music and cognitive functions is more than impressive, thanks to the findings from the emerging field of music cognition and neuromusicology. Indulging in music is considered as an exercise of cognitive flexibility. Creatively working with various dynamic features of music such as pitch and rhythm is known to involve attentional networks and executive functions. Since music is known to involve all known cognitive processes, as a biological phenomenon, it is viewed as an "honest signal" for cognitive and emotional flexibility and fitness (62). Temporal cues in music and rhythm engage not only the motor system but play a crucial role in arousal, orientation, and sustenance of attention. Rhythmic patterns synchronize with the internal oscillators in accordance with its temporal regularity, thereby having its effect on attentional processes (63-66). Similarly, music provides a temporal-metrical structure that facilitates perceptual grouping and chunking of the information being processed or learnt as well as can be used as a mnemonic device in memory formation. Listening to polyphonic music has shown to engage neural circuits underlying multiple forms of working memory, attention, semantic processing, target detection, and motor imagery, in turn indicating that music listening engages brain areas that are involved in general functions rather than music-specific areas (67). Music also engages all limbic and paralimbic brain areas, which are crucial in evoking, maintaining, and modulating emotion $(51,68,69)$. It seems plausible that engaging in music would not only stimulate the various centers of the brain including the emotion areas but music can also be systematically used in altering and regulating the cognitive processes involved, which can be further generalized to non-musical domains of functioning. So much so, musicians are considered as the best model to study neural plasticity due to the effects of intense training involving sensorimotor training such as music (70, 71). A schematic representation of the effect of music on the functioning of the brain and the various domains of functioning affected in TBI addressed by music therapy is presented as Figure 1 .

\section{NEUROLOGIC MUSIC THERAPY}

Findings from the field of neuroscience have provided an edifice leading to the development of a science-based approach to music therapy practice and research. This has been termed as neurologic music therapy (NMT). NMT is defined as "the therapeutic application of music to cognitive, sensory, and motor dysfunctions due to neurologic disease of the human nervous system" (43, 44, 72). NMT is based on the "rational scientific mediation model" (RSMM). This dynamic model was conceptualized to develop a systematic epistemology for translational research, linking scientific findings in neurological, psychological, and physiological foundations of music cognition and production to rehabilitation of functions in the non-music domain. NMT techniques are standardized in its terminology and application, thereby lending itself for systematic research studies. Standardized techniques and application procedures had eluded music therapy in the past $(43,44$, 56). NMT techniques, hitherto have been designed to address three areas of functioning, viz.,

- Sensorimotor functioning: aims at rehabilitating motor functions, mobility, strength, endurance, cadence, and co-ordination of gross and fine motor movements in lower and upper extremities $(43,73)$.

- Speech and language functioning: aims at rehabilitating vocal control, speech production, and meaningful usage of verbal and non-verbal symbols in communication $(43,74)$.

- Cognitive functioning: aims at rehabilitating basic and higher order cognitive functions such as attention, memory, executive functions, and psychosocial skills $(43,72,75)$. A brief overview on the specific techniques developed toward remediation of cognitive functions is listed in Table 1.

The CR techniques via NMT is also based on the "transformational design model" (TDM) that brings together traditional cognitive rehabilitation approaches with music therapy approaches. First of all, CR via NMT begins with the first of a systematic neuropsychological evaluation to outline the specific area that requires therapeutic attention. Following this, the therapeutic goals and objectives are set. Then, the non-musical exercises in the traditional CR approach are enriched with the techniques of NMT. The final goal is to facilitate transference of improved cognitive function to non-musical domains of functioning and everyday functioning. This is targeted by providing home-work exercises with the aim of enabling generalization to everyday situation $(44,75)$.

Neurologic music therapy has shown promising results in remediation of motor functioning such as arm and gait control in patients suffering from stroke, Parkinson's disease, cerebral palsy (76-78), and speech and language rehabilitation in various neurological conditions $(40,79,80)$. CR is the most recent domain to be addressed via NMT. The systematic approach in this direction has spurred from the evidence that music and rhythm engage not just the motor system but also cognitive functions. The present paper will limit its focus on the third area of functioning, the cognitive functioning specific to its application TBI. 


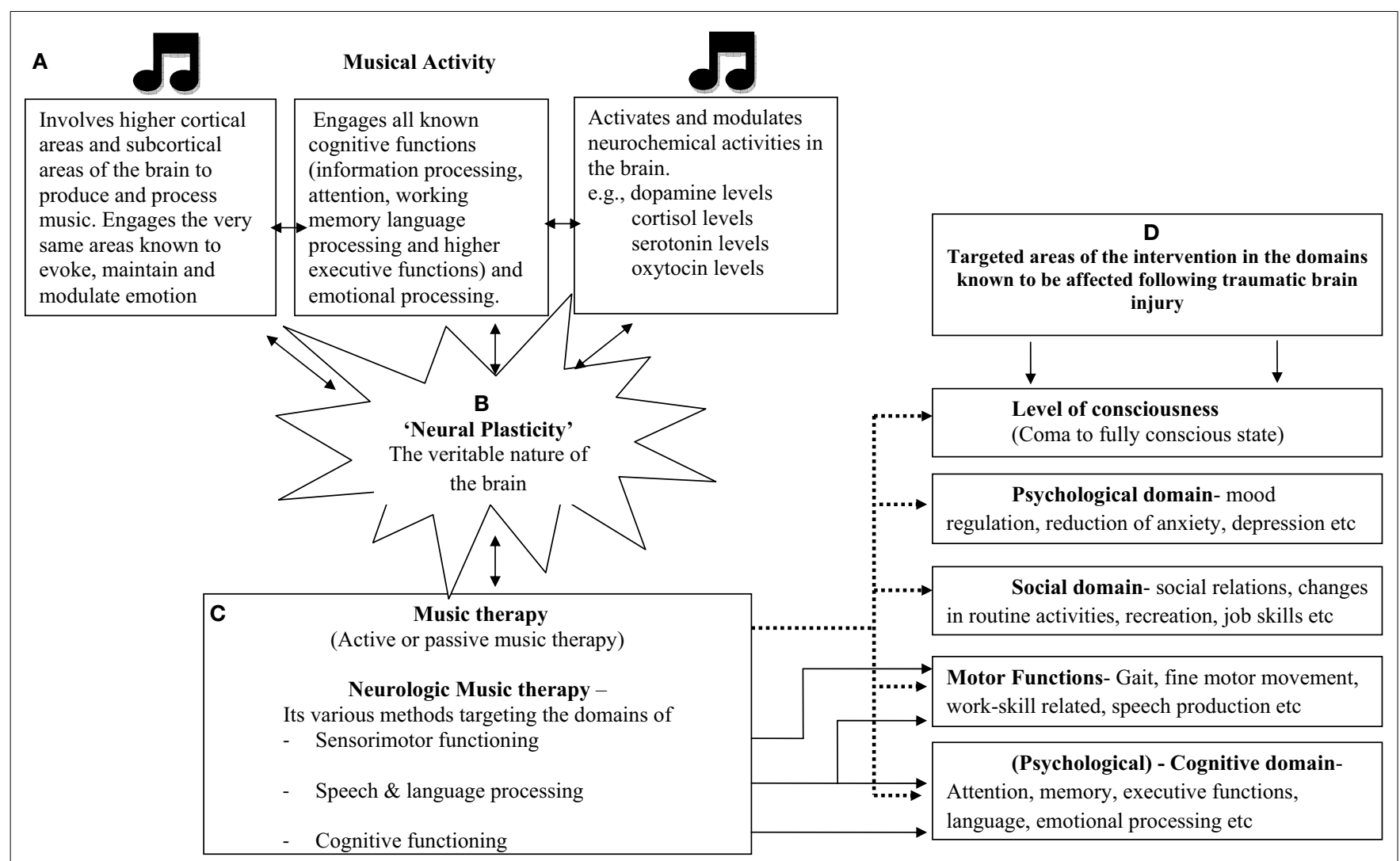

FIGURE 1 | Schematic representation of the effect of music on neural, cognitive, neurochemical functions, and how music therapy which involves musical-based activities (active and passive) has effect on various domains of functions known to be affected following traumatic brain injury. Few key references under each section: (A) $(46,48,49,58,60$, 85); (B) $(57,70,71,86-88)$; (C) $(43,44)$; (D) $(33,34,36,39,76,89,90)$

\section{MUSIC-BASED COGNITIVE REMEDIATION IN TBI, THE JOURNEY SO FAR}

Despite the strong evidence linking music and its effect on cognition and emotion, by far, scientific evidence for effectiveness of music as to improve cognition in TBI is surprisingly weak with only a few studies and no randomized controlled trials. A review on music therapy literature indicates that only a handful of research have examined music therapy for CR in neurological conditions and far lesser studies carried out in TBI $(33,81-83)$. A systematic review on music therapy in acquired brain injury examined seven studies which were either randomized or quasi-randomized controlled trials with a total of 184 participants showed that rhythmic auditory stimulation (RAS) was effective in improving gait parameters including gait velocity, stride strength, cadence, and gait symmetry in acquired brain injury conditions. This review study could not comment on the effect of music therapy on other outcomes such as upper extremity motor function, speech, pain perception, and behavioral (agitation) and cognitive orientation due to insufficient data (84). This meta-analytic study examining effectiveness of music therapy for acquired brain-injured conditions found only a handful of randomized controlled group studies and none of the studies included in the final data analysis examined CR in TBI (84). So far, there has been only one study examining remediation of executive functions in TBI using music therapy. This preliminary study using a quasi experimental design examined the immediate effect of NMT in a group-setting on patients with brain injury. Of the treatment group included $(n=31), 77.42 \%$ of patients had TBI and the remaining sample were patients with cerebrovascular accident $(12.90 \%)$, seizure disorder $(6.45 \%)$, and brain tumor $(3.23 \%)$. The treatment group received four brief sessions of NMT lasting for $30 \mathrm{~min}$ duration and each session targeted one of the following functions: attention, memory, executive functions, and emotional adjustment. The control group patients $(n=23)$ received rest period for the same duration in a quiet room for a period of 4 days. The control group participants comprised of patients with TBI (86.95\% of the sample), cerebrovascular accident $(4.35 \%)$, and toxic exposure $(8.70 \%)$. The study showed that NMT was effective in bringing about significant positive changes in the domains of executive functions, mental flexibility to be specific with a large effect size $(d=1.21)$, and significant decrease in depressed mood with a medium effect size $(d=0.52)$ and anxiety although with a small effect size $(d=0.28)$. This brief single session intervention did not bring about significant changes in attention and memory (33). The study did not examine sustenance of improved functions over time. The findings emphasize the need for longer duration of intervention especially for cognitive functions such as attention and memory. 
Table 1 | Brief overview on the techniques of NMT under each of the cognitive domain targeted for intervention.

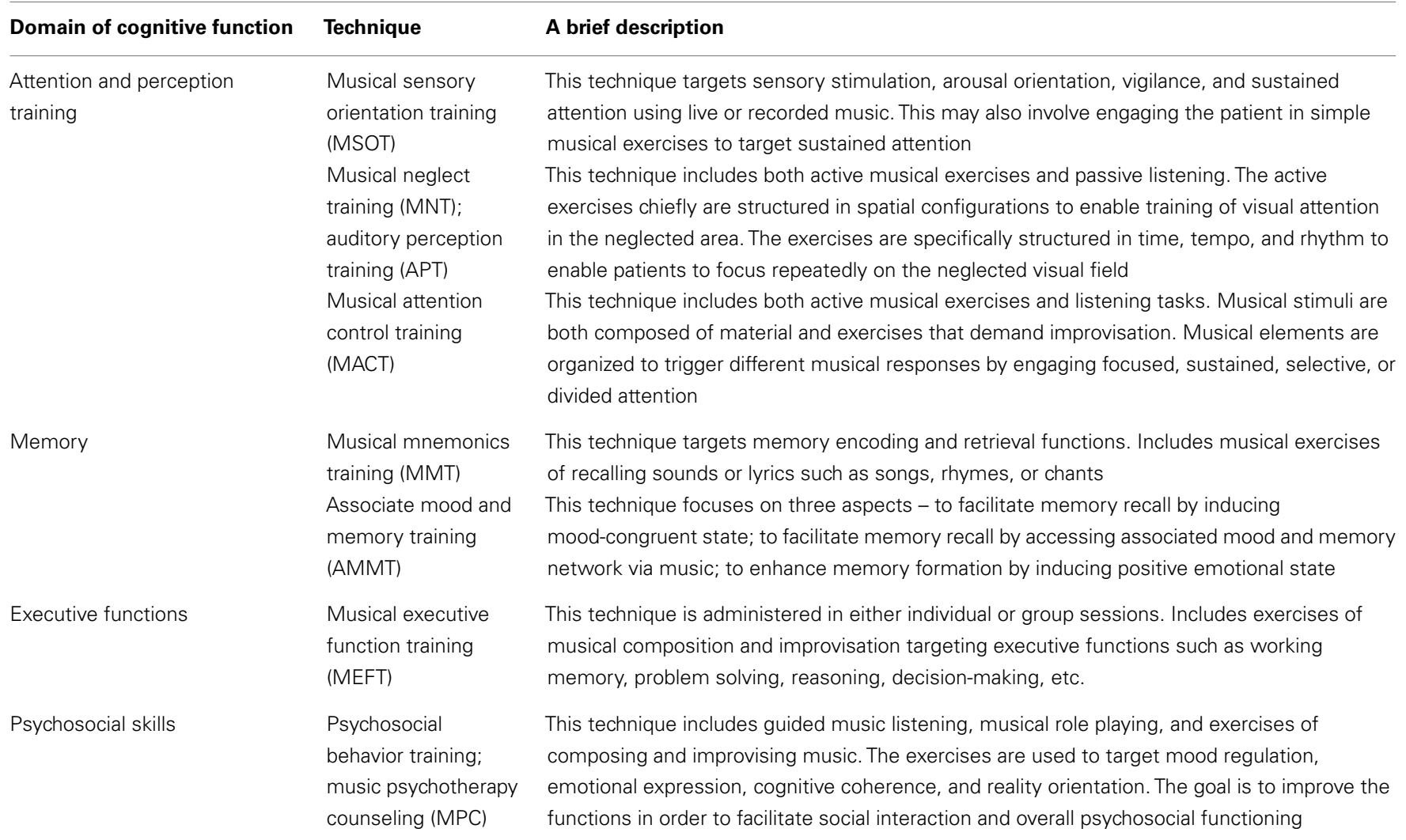

For detailed description of each of the techniques, kindly refer to Ref. (43, 75).

\section{CONCLUSION}

Outcome research on music-based CR in TBI is in its infancy. There is a gap between theoretical understanding of potential role of music as a CR method and systematic evaluation of its efficacy in TBI patients. With exponential growth in the scientific evidence in linking music and cognitive functions, the gap in application of music in CR in TBI would definitely be a temporary phenomenon. So far, the set-back in carrying out such research studies may be due to the very abstract nature of music and limited understanding of the link between music and specific cognitive functions. A clearer understanding of music engaging a host of cognitive process has been possible over the past two to three decades with the emergence of scientific evidence from the fields of neuromusicology and music cognition. Until this time, there was an overpowering view of music as a therapeutic method for enhancing well-being with greater emphasis on emotional components in therapy. In addition, the difficulty may have been due to the very heterogeneous nature of TBI with varied cognitive profile. NMT methods have been successful in designing methods and techniques to address specific cognitive functions, even by circumventing the emotional component of music in the therapeutic setting. Additional markers such as neurochemical changes following NMT, such as BDNF or functional changes observed using methods such as fMRI, EEG/ERP would add to the scientific strength of the future investigations. It would not be too long before the effectiveness of NMT methods to improve cognitive functions is systematically evaluated in TBI as well as other neurological and neurosurgical conditions. A ubiquitous phenomenon like music and systematic techniques such the NMT can be main-stream holistic treatment method in TBI and other clinical conditions.

\section{REFERENCES}

1. Khan F, Baguley IJ, Cameron ID. Rehabilitation after traumatic brain injury. Med J Aust (2003) 178:290-5.

2. McDonald S. Impairments in social cognition following severe traumatic brain injury. J Int Neuropsychol Soc (2013) 19:231-46. doi:10.1017/ S1355617712001506

3. Morton MV, Wehman P. Psychosocial and emotional sequelae of individuals with traumatic brain injury: a literature review and recommendations. Brain Inj (1995) 9:81-92. doi:10.3109/02699059509004574

4. Bond MR. Assessment of the psychosocial outcome after severe head injury. Ciba Found Symp (1975) 34:141-57.

5. Draper K, Ponsford J. Cognitive functioning ten years following traumatic brain injury and rehabilitation. Neuropsychology (2008) 22:618-25. doi:10.1037/08944105.22.5.618

6. Flanagan SR, Cantor JB, Ashman TA. Traumatic brain injury: future assessment tools and treatment prospects. Neuropsychiatr Dis Treat (2008) 4:877-92. doi:10.2147/NDT.S1985

7. Chua KS, Ng YS, Yap SG, Bok CW. A brief review of traumatic brain injury rehabilitation. Ann Acad Med Singapore (2007) 36(1):31-42.

8. McAllister TW. Neurobehavioral sequelae of traumatic brain injury: evaluation and management. World Psychiatry (2008) 7(1):3-10.

9. Spitz G, Ponsford JL, Rudzki D, Maller JJ. Association between cognitive performance and functional outcome following traumatic brain injury: a longitudinal multilevel examination. Neuropsychology (2012) 26:604-12. doi:10.1037/ a0029239 
10. Gordon WA, Zafonte R, Cicerone K, Cantor J, Brown M, Lombard L, et al. Traumatic brain injury rehabilitation: state of the science. Am J Phys Med Rehabil (2006) 85:343-82. doi:10.1097/01.phm.0000202106.01654.61

11. Cicerone KD, Dahlberg C, Malec JF, Langenbahn DM, Felicetti T, Kneipp S, et al. Evidence-based cognitive rehabilitation: updated review of the literature from 1998 through 2002. Arch Phys Med Rehabil (2005) 86:1681-92. doi:10.1016/j.apmr.2005.03.024

12. Cicerone KD, Langenbahn DM, Braden C, Malec JF, Kalmar K, Fraas M, et al. Evidence-based cognitive rehabilitation: updated review of the literature from 2003 through 2008. Arch Phys Med Rehabil (2011) 92:519-30. doi:10.1016/j. apmr.2010.11.015

13. Rohling ML, Faust ME, Beverly B, Demakis G. Effectiveness of cognitive rehabilitation following acquired brain injury: a meta-analytic re-examination of Cicerone et al.'s $(2000,2005)$ systematic reviews. Neuropsychology (2009) 23:20. doi:10.1037/a0013659

14. Volpe BT, McDowell FH. The efficacy of cognitive rehabilitation in patients with traumatic brain injury. Arch Neurol (1990) 47:220-2. doi:10.1001/archneur. 1990.00530020128026

15. Cicerone KD, Dahlberg C, Kalmar K, Langnbahn DM, Malec JF, Berquist TF, et al. Evidence-based cognitive rehabilitation: recommendations for clinical practice. Arch Phys Med Rehabil (2000) 81:1596-615. doi:10.1053/apmr.2000. 19240

16. Diller L, Gordon WA. Interventions for cognitive deficits in brain-injured adults. J Consult Clin Psychol (1981) 49:822-34. doi:10.1037/0022-006X.49.6.822

17. Gordon WA. Methodological considerations in cognitive remediation. In: Meier MJ, Benton AL, Diller L, editors. Neuropsychological Rehabilitation. Edinburgh: Churchill Livingstone Inc., Longman UK Ltd. (1987). p. 111-31.

18. Trexler LE, Webb MP, Zappala G. Strategic aspects of neuropsychological rehabilitation. In: Christensen AL, Uzzell BP, editors. Brain Injury and Neuropsychological Rehabilitation: International Perspectives. New Jersey: Lawrence Erlbaum Associates Inc publishers (1994).

19. Wilson BA. Cognitive rehabilitation: how it is and how it might be. J Int Neuropsychol Soc (1997) 3:487-96.

20. Prigatano GP. Learning from our successes and failures: reflections and comments on "cognitive rehabilitation: how it is and how it might be". J Int Neuropsychol Soc (1997) 3:497-9.

21. Cicerone KD, Mott T, Azulay J, Sharlow-Galella MA, Ellmo WJ, Paradise S, et al. A randomized controlled trial of holistic neuropsychologic rehabilitation after traumatic brain injury. Arch Phys Med Rehabil (2008) 89:2239-49. doi:10.1016/j.apmr.2008.06.017

22. Ben-Yishay Y, Prigatana GP. Cognitive remediation. 2nd ed. In: Rosenthal M, Bond MR, Griffith ER, Miller JD, editors. Rehabilitation of the Adult and Child with Traumatic Brain Injury. Philadelphia, PA: FA Davis (1990). 38 p.

23. Cappa SF, Benke T, Clarke S, Rossi B, Stemmer B, Van Heugten CM. EFNS guidelines on cognitive rehabilitation: report of an EFNS task force. Eur J Neurol (2005) 12:665-80. doi:10.1111/j.1468-1331.2005.01330.x

24. Cernich AN, Kurtz SM, Mordecai KL, Ryan PB. Cognitive rehabilitation in traumatic brain injury. Curr Treat Options Neurol (2010) 12:412-23. doi:10.1007/ s11940-010-0085-6

25. van Heugten C, Gregorio GW, Wade D. Evidence-based cognitive rehabilitation after acquired brain injury: a systematic review of content of treatment. Neuropsychol Rehabil (2012) 22:653-73. doi:10.1080/09602011.2012.680891

26. Mateer CA, Kerns KA, Eso KL. Management of attention and memory disorders following traumatic brain injury. J Learn Disabil (1996) 29:618-32. doi: $10.1177 / 002221949602900606$

27. Park NW, Ingles JL. Effectiveness of attention rehabilitation after an acquired brain injury: a meta-analysis. Neuropsychology (2001) 15:199. doi:10.1037/08944105.15.2.199

28. Mateer CA. The rehabilitation of executive disorders. In: Stuss DT, Winocur G, Robertson IH, editors. Cognitive Neurorehabilitation. Cambridge: Cambridge University Press (1999). p. 314-32.

29. Chung CS, Pollock A, Campbell T, Durward BR, Hagen S. Cognitive rehabilitation for executive dysfunction in adults with stroke or other adult non-progressive acquired brain damage. Cochrane Database Syst Rev (2013) 4:CD008391. doi:10.1002/14651858.CD008391.pub2

30. Schutz LE, Trainor K. Evaluation of cognitive rehabilitation as a treatment paradigm. Brain Inj (2007) 21:545-57. doi:10.1080/02699050701426923
31. Middleton EL, Schwartz MF. Errorless learning in cognitive rehabilitation: a critical review. Neuropsychol Rehabil (2012) 22:138-68. doi:10.1080/09602011. 2011.639619

32. Hurt CP, Rice RR, McIntosh GC, Thaut MH. Rhythmic auditory stimulation in gait training for patients with traumatic brain injury. J Music Ther (1998) 35:228-41. doi:10.1093/jmt/35.4.228

33. Thaut MH, Gardiner JC, Holmberg D, Horowitz J, Kent L, Andrews G, et al. Neurologic music therapy improves executive function and emotional adjustment in traumatic brain injury rehabilitation. Ann N Y Acad Sci (2009) 1169:406-16. doi:10.1111/j.1749-6632.2009.04585.x

34. Magee LW. The effect of music therapy on mood states in neurological patients: a pilot study. J Music Ther (2002) 39:20-9. doi:10.1093/jmt/39.1.20

35. Särkämö T, Tervaniemi M, Laitinen S, Forsblom A, Soinila S, Mikkonen M, et al. Music listening enhances cognitive recovery and mood after middle cerebral artery stroke. Brain (2008) 131:866-76. doi:10.1093/brain/awn013

36. Guétin S, Soua B, Voiriot G, Picot MC, Hérisson C. The effect of music therapy on mood and anxiety-depression: an observational study in institutionalised patients with traumatic brain injury. Ann Phys Rehabil Med (2009) 52:30-40. doi:10.1016/j.annrmp.2008.08.009

37. Lancioni GE, Bosco A, Belardinelli MO, Singh NN, O’Reilly MF, Sigsfoos J. An overview of intervention options for promoting adaptive behavior of persons with acquired brain injury and minimally conscious state. Res Dev Disabil (2010) 31:1121-34. doi:10.1016/j.ridd.2010.06.019

38. Krout RE. Music listening to facilitate relaxation and promote wellness: integrated aspects of our neurophysiological responses to music. Arts Psychother (2007) 34:134-41. doi:10.1016/j.aip.2006.11.001

39. Bower J, Catroppa C, Grocke D, Shoemark H. Music therapy for early cognitive rehabilitation post-childhood TBI: an intrinsic mixed methods case study. Dev Neurorehabil (2013). doi:10.3109/17518423.2013.778910

40. Schlaug G, Norton A, Marchina S, Zipse L, Wan CY. From singing to speaking: facilitating recovery from nonfluent aphasia. Future Neurol (2010) 5:657-65. doi:10.2217/fnl.10.44

41. Baker F, Wigram T, Gold C. The effects of a song-singing programme on the affective speaking intonation of people with traumatic brain injury. Brain Inj (2005) 19:519-28. doi:10.1080/02699050400005150

42. Morton LL, Kreshner JR, Siegel LS. The potential for therapeutic application of music on problems related to memory and attention. J Music Ther (1990) 27:195-208. doi:10.1093/jmt/27.4.195

43. de l'Etoile SK. Neurologic music therapy: a scientific paradigm for clinical practice. Music Med (2010) 2:78-84. doi:10.1177/1943862110364232

44. Thaut MH. Music in Therapy and Medicine: From Social Science to Neuroscience. New York: Routledge; Taylor and Francis group (2005).

45. Koelsch S, Fuermetz J, Sack U, Bauer K, Hohenadel M, Wiegel M, et al. Effects of music listening on cortisol levels and propofol consumption during spinal anaesthesia. Front Psychol (2011) 2:58. doi:10.3389/fpsyg.2011.00058

46. Suda M, Morimoto K, Obata A, Koizumi H, Maki A. Emotional responses to music: towards scientific perspectives on music therapy. Neuroreport (2008) 19(1):75-8. doi:10.1097/WNR.0b013e3282f3476f

47. Khalfa S, Bella SD, Roy M, Peretz I, Lupein SJ. Effects of relaxing music on salivary cortisol level after psychological stress. Ann N Y Acad Sci (2003) 999:374-6. doi:10.1196/annals.1284.045

48. Chanda ML, Levitin DJ. The neurochemistry of music. Trends Cogn Sci (2013) 17:179-93. doi:10.1016/j.tics.2013.02.007

49. Fukui H, Toyoshima K. Music facilitate the neurogenesis, regeneration and repair of neuron. Med Hypotheses (2008) 71:765-9. doi:10.1016/j.mehy.2008.06.019

50. Salimpoor VN, Benovoy M, Larcher K, Dagher A, Zatorre RJ. Anatomically distinct dopamine release during anticipation and experience of peak emotion to music. Nat Neurosci (2011) 14:257-62. doi:10.1038/nn.2726

51. Blood AJ, Zatorre RJ. Intensely pleasurable responses to music correlate with activity in brain regions implicated in reward and emotion. Proc Natl Acad Sci US A (2001) 98:11818-23. doi:10.1073/pnas.191355898

52. Menon V, Levitin, DJ. The rewards of music listening: response and physiological connectivity of the mesolimbic system. Neuroimage (2005) 28:175-84. doi:10.1016/j.neuroimage.2005.05.053

53. Salimpoor VN, van den Bosch I, Kovacevic N, McIntosh AR, Dagher A, Zatorre RJ. Interactions between the nucleus accumbens and auditory cortices predict music reward value. Science (2013) 340:216-9. doi:10.1126/science.1231059 
54. Koelsch S. A neuroscientific perspective on music therapy. Ann N Y Acad Sci (2009) 1169:374-84. doi:10.1111/j.1749-6632.2009.04592.x

55. Hillecke T, Nickel A, Bolay HV. Scientific perspectives on music therapy. Ann N Y Acad Sci (2005) 1060:271-82. doi:10.1196/annals.1360.020

56. Thaut MH. Neurologic music therapy in cognitive rehabilitation. Music Percept (2010) 27:281-5. doi:10.1525/mp.2010.27.4.281

57. Schlaug G. Part VI introduction: listening to and making music facilitates brain recovery processes. Ann N Y Acad Sci (2009) 1169:372-3. doi:10.1111/j.17496632.2009.04869.x

58. Peretz I, Zatorre RJ. Brain organization for music processing. Annu Rev Psychol (2005) 56:89-114. doi:10.1146/annurev.psych.56.091103.070225

59. Zatorre R, McGill J. Music, the food of neuroscience? Nature (2005) 434:312-5. doi:10.1038/434312a

60. Levitin DJ, Tirovolas AK. Current advances in the cognitive neuroscience of music. Ann N Y Acad Sci (2009) 1156:211-31. doi:10.1111/j.1749-6632.2009. 04417.x

61. Patel AD. Music, biological evolution, and the brain. In: Bailar M, editor. Emerging Disciplines. Houston, TX: Rice University Press (2010). p. 91-144.

62. Peretz I. The nature of music from a biological perspective. Cognition (2006) 100:1-32. doi:10.1016/j.cognition.2005.11.004

63. Jones MR, Boltz M. Dynamic attending and responses to time. Psychol Rev (1989) 96:459-91. doi:10.1037/0033-295X.96.3.459

64. Jones MR. Musical time. In: Hallam S, Cross I, Thaut MH, editors. The Oxford Handbook of Music Psychology. Oxford: Oxford Psychology Press (2008). p. 8192.

65. Janata P, Grafton ST. Swinging in the brain: shared neural substrates for behaviors related to sequencing and music. Nat Neurosci (2003) 6:682-7. doi:10.1038/nn1081

66. Zatorre RJ, Chen JL, Penhune VB. When the brain plays music: auditory-motor interactions in music perception and production. Nat Rev Neurosci (2007) 8:547-58. doi:10.1038/nrn2152

67. Janata P, Tillmann B, Bharucha JJ. Listening to polyphonic music recruits domain-general attention and working memory circuits. Cogn Affect Behav Neurosci (2002) 2:121-40. doi:10.3758/CABN.2.2.121

68. Brown S, Martinez MJ, Parsons LM. Passive music listening spontaneously engages limbic and paralimbic systems. Neuroreport (2004) 15:2033-7. doi:10. 1097/00001756-200409150-00008

69. Koelsch S. Towards a neural basis of music-evoked emotions. Trends Cogn Sci (2010) 14:131-7. doi:10.1016/j.ridd.2010.06.019

70. Wan CY, Schlaug G. Music making as a tool for promoting brain plasticity across the life span. Neuroscientist (2010) 16(5):566-77. doi:10.1177/ 1073858410377805

71. Merrett DL, Peretz I, Wilson SJ. Moderating variables of music traininginduced neuroplasticity: a review and discussion. Front Psychol (2013) 4:606. doi:10.3389/fpsyg.2013.00606

72. Clair AA, Pasiali V, Lagasse B. Neurologic music therapy. 2nd ed. In: Darrow AA, editor. Introduction to Approaches in Music Therapy. Silver Spring, MD: The American Music Therapy Association (2008). p. 153-72.

73. Thaut MH. Neurologic music therapy in sensorimotor rehabilitation. In: Thaut MH, editor. Rhythm, Music and the Brain. New York: Routledge; Taylor and Francis group (2005). p. 137-64.

74. Thaut MH. Neurologic music therapy in speech and language rehabilitation. In: Thaut MH, editor. Rhythm, Music and the Brain. New York: Routledge; Taylor and Francis group (2005). p. 165-78.

75. Thaut MH. Neurologic music therapy in cognitive rehabilitation. In: Thaut $\mathrm{MH}$, editor. Rhythm, Music and the Brain. New York: Routledge; Taylor and Francis group (2005). p. 179-202.

76. Thaut MH, Leins AK, Rice RR, Argstatter H, Kenyon GP, McIntosh GC, et al. Rhythmic auditory stimulation improves gait more than NDT/Bobath training in near-ambulatory patients early poststroke: a single-blind, randomized trial. Neurorehabil Neural Repair (2007) 21:455-9. doi:10.1177/1545968307300523
77. Kim SJ, Kwak EE, Park ES, Cho SR. Differential effects of rhythmic auditory stimulation and neurodevelopmental treatment/Bobath on gait patterns in adults with cerebral palsy: a randomized controlled trial. Clin Rehabil (2012) 26:904-14. doi:10.1177/0269215511434648

78. Wittwer JE, Webster KE, Hill K. Rhythmic auditory cueing to improve walking in patients with neurological conditions other than Parkinson's disease - what is the evidence? Disabil Rehabil (2013) 35:164-76. doi:10.3109/09638288.2012.690495

79. Schlaug G, Marchina S, Norton A. Evidence for plasticity in white-matter tracts of patients with chronic Broca's aphasia undergoing intense intonation-based speech therapy. Ann NYAcad Sci (2009) 1169:385-94. doi:10.1111/j.1749-6632. 2009.04587.x

80. Tamplin J. A pilot study into the effect of vocal exercises and singing on dysarthric speech. NeuroRehabilitation (2008) 23(3):207-16.

81. Jeong E, Lesiuk TL. Development and preliminary evaluation of a music-based attention assessment for patients with traumatic brain injury. J Music Ther (2011) 48:551-72. doi:10.1093/jmt/48.4.551

82. Knox R, Yokota-Adachi H, Kreshner J, Jutai J. Musical attention training program and alternating attention in brain injury: an initial report. Music Ther Perspect (2003) 21:99-104. doi:10.1093/mtp/21.2.99

83. Knox R, Jutai J. Music-based rehabilitation of attention following brain injury. Can J Rehabil (1996) 9:169-81.

84. Bradt J, Magee WL, Dileo C, Wheeler BL, McGilloway E. Music therapy for acquired brain injury. Cochrane Database Syst Rev (2010) 7:CD006787. doi:10.1002/14651858.CD006787.pub2

85. Schmithorst VJ. Separate cortical networks involved in music perception: preliminary functional MRI evidence for modularity of music processing. $\mathrm{Neu}$ roimage (2005) 25(2):444-51. doi:10.1016/j.neuroimage.2004.12.006

86. Ellis RJ, Norton AC, Overy K, Winner E, Alsop DC, Schlaug G. Differentiating maturational and training influences on $\mathrm{fMRI}$ activation during music processing. Neuroimage (2012) 60(3):1902-12. doi:10.1016/j.neuroimage.2012.01.138

87. Ellis RJ, Bruijn B, Norton AC, Winner E, Schlaug G. Training-mediated leftward asymmetries during music processing: a cross-sectional and longitudinal fMRI analysis. Neuroimage (2013) 75:97-107. doi:10.1016/j.neuroimage.2013.02.045

88. Hyde KL, Lerch J, Norton A, Forgeard M, Winner E, Evans AC, et al. Musical training shapes structural brain development. JNeurosci (2009) 29(10):3019-25. doi:10.1523/JNEUROSCI.5118-08.2009

89. Baker F, Roth EA. Neuroplasticity and functional recovery: training models and compensatory strategies in music therapy. Nordic J Music Ther (2004) 13(1):20-32. doi:10.1080/08098130409478095

90. Nayak S, Wheeler BL, Shiflett SC, Agostinelli S. Effect of music therapy on mood and social interaction among individuals with acute traumatic brain injury and stroke. Rehabil Psychol (2000) 45(3):274. doi:10.1037/0090-5550.45. 3.274

Conflict of Interest Statement: The author declares that the research was conducted in the absence of any commercial or financial relationships that could be construed as a potential conflict of interest.

Received: 01 January 2014; paper pending published: 15 February 2014; accepted: 10 March 2014; published online: 24 March 2014.

Citation: Hegde S (2014) Music-based cognitive remediation therapy for patients with traumatic brain injury. Front. Neurol. 5:34. doi: 10.3389/fneur.2014.00034

This article was submitted to Neurotrauma, a section of the journal Frontiers in Neurology.

Copyright (c) 2014 Hegde. This is an open-access article distributed under the terms of the Creative Commons Attribution License (CC BY). The use, distribution or reproduction in other forums is permitted, provided the original author(s) or licensor are credited and that the original publication in this journal is cited, in accordance with accepted academic practice. No use, distribution or reproduction is permitted which does not comply with these terms. 